\title{
Sources of variations in total column carbon dioxide
}

\author{
G. Keppel-Aleks, P. O. Wennberg, and T. Schneider \\ California Institute of Technology, Pasadena, California, USA \\ Received: 11 November 2010 - Published in Atmos. Chem. Phys. Discuss.: 16 December 2010 \\ Revised: 15 March 2011 - Accepted: 24 March 2011 - Published: 18 April 2011
}

\begin{abstract}
Observations of gradients in the total $\mathrm{CO}_{2}$ column, $\left\langle\mathrm{CO}_{2}\right\rangle$, are expected to provide improved constraints on surface fluxes of $\mathrm{CO}_{2}$. Here we use a general circulation model with a variety of prescribed carbon fluxes to investigate how variations in $\left\langle\mathrm{CO}_{2}\right\rangle$ arise. On diurnal scales, variations are small and are forced by both local fluxes and advection. On seasonal scales, gradients are set by the north-south flux distribution. On synoptic scales, variations arise due to large-scale eddy-driven disturbances of the meridional gradient. In this case, because variations in $\left\langle\mathrm{CO}_{2}\right\rangle$ are tied to synoptic activity, significant correlations exist between $\left\langle\mathrm{CO}_{2}\right\rangle$ and dynamical tracers. We illustrate how such correlations can be used to describe the north-south gradients of $\left\langle\mathrm{CO}_{2}\right\rangle$ and the underlying fluxes on continental scales. These simulations suggest a novel analysis framework for using column observations in carbon cycle science.
\end{abstract}

\section{Introduction}

Diagnosing the patterns and trends in the flux of carbon dioxide, $\mathrm{CO}_{2}$, between the land or ocean and the atmosphere is a longstanding interest of the carbon cycle community. Such information is needed, for example, to evaluate models of future climate and for evaluating the effectiveness of proposed climate change mitigation strategies.

Direct measurements of fluxes can be made on small spatial scales, but global accounting requires either extrapolation of regional-scale flux observations or use of atmospheric observations of $\mathrm{CO}_{2}$ to infer fluxes indirectly. Inverse modeling represents one approach for estimating regional and global carbon fluxes from gradients in the observed concentration (or mixing ratio) of $\mathrm{CO}_{2},\left[\mathrm{CO}_{2}\right]$ (Gurney et al., 2002, 2004).

Correspondence to: G. Keppel-Aleks (gka@alum.mit.edu)
Typically, atmospheric transport models are used to simulate global $\mathrm{CO}_{2}$ fields, given estimates of regional $\mathrm{CO}_{2}$ fluxes owing to fossil fuel emissions, ocean-atmosphere exchange, and biosphere-atmosphere exchange; the estimated fluxes are then adjusted to best match the observations.

Accurate estimation of $\mathrm{CO}_{2}$ fluxes using inverse techniques is quite challenging. The sparseness of the data set and the fact that most observations are from the surface or near the surface place considerable demands on the accuracy of the velocity fields in the transport model (Denning et al., 1995). In particular, studies have illustrated that the inference of regional fluxes is highly sensitive to the representation of subgrid-scale boundary layer dynamics in transport models (Stephens et al., 2007). The use of surface $\left[\mathrm{CO}_{2}\right]$ observations in such studies is further complicated by the diurnal and seasonal "rectifier effect", the covariance between surface $\mathrm{CO}_{2}$ fluxes and the strength of vertical mixing (Denning et al., 1995). In contrast, column data provide a constraint on the total mass of $\mathrm{CO}_{2}$ in a column, and so are more closely related to the underlying fluxes. Observations of column $\mathrm{CO}_{2}$ from remote sensing platforms such as GOSAT and OCO-2 (Yokota et al., 2009; Crisp et al., 2004) and from ground-based observatories are anticipated to provide better constraints on the exchange of $\mathrm{CO}_{2}$ between the atmosphere and the surface (Olsen and Randerson, 2004; Chevallier et al., 2007).

Observed variations of atmospheric $\mathrm{CO}_{2}$ in time and space are the fundamental data constraint in all inverse studies. Studies suggest that gradients in free tropospheric $\mathrm{CO}_{2}$ concentrations can differ substantially from gradients at the surface (Miyazaki et al., 2008, 2009). Here, we examine how variations in the total $\mathrm{CO}_{2}$ column, $\left\langle\mathrm{CO}_{2}\right\rangle$, arise. In particular, we investigate how local, regional, and global fluxes are expressed in variations in $\left\langle\mathrm{CO}_{2}\right\rangle$. We use a global general circulation model (GCM) with prescribed fluxes to determine how changes in the pattern of fluxes alter the global fields. We show that local fluxes have a relatively small impact on

Published by Copernicus Publications on behalf of the European Geosciences Union. 
the variability in the local column. In contrast, a substantial fraction of both the local and regional scale variability in a column arises from advection of global-scale gradients by weather systems. We describe several meteorological diagnostics that allow this variability to be quantified. In a subsequent manuscript, in preparation for Biogeosciences, we will apply these diagnostics to observed $\left\langle\mathrm{CO}_{2}\right\rangle$.

\section{Methods}

We simulate $\mathrm{CO}_{2}$ fields with a GCM, using standard surface fluxes as boundary conditions. We use the AM2 GCM developed at NOAA's Geophysical Fluid Dynamics Laboratory (Anderson et al., 2004). AM2 is a free-running GCM with prescribed sea surface temperatures. It uses a finite-volume dynamical core, which conserves mass better than a spectral model and is thus well-suited for tracer-transport simulations (Lin, 2004). In multi-year runs, the total mass of the atmosphere changes by less than $1 \mathrm{ppm}$ over one year. We run the model at $2^{\circ}$ latitude by $2.5^{\circ}$ longitude resolution with 25 vertical levels using a hybrid pressure-sigma coordinate.

Biosphere-atmosphere exchange in our simulations is based on monthly Carnegie Ames Stanford Approach (CASA) net ecosystem exchange (NEE) (Randerson et al., 1997). NEE represents the residual of monthly net primary production (NPP) and respiration fluxes that have been redistributed at 3 hour resolution based on 2001 climatology (Olsen and Randerson, 2004). The net annual exchange is approximately zero at each grid box (i.e., "balanced" biosphere); it does not interact with AM2 climatology. Zonallyintegrated CASA NEE is shown in Fig. 1a, and the resulting biospheric $\left\langle\mathrm{CO}_{2}\right\rangle$ in Fig. 1b. Ocean exchange, shown in Fig. 2a, is based on monthly-mean fluxes derived from surface ocean $p \mathrm{CO}_{2}$ data (Takahashi et al., 2002). The ocean fluxes we use represent an annual and global mean sink of atmospheric $\mathrm{CO}_{2}$ of $\sim 1.4 \mathrm{PgCy}^{-1}$. Resulting oceanic $\left\langle\mathrm{CO}_{2}\right\rangle$ is shown in Fig. 2b. Fossil emissions in the model are annual mean emissions for the year 1990 (Andres et al., 1996), when net global emissions were 5.5 $\mathrm{Pg} \mathrm{Cy}^{-1}$. These emissions are determined from self-reported fuel consumption at the national level and converted to regional fluxes proportional to local population density (Marland and Rotty, 1984).

We integrate output from the model to determine the vertically averaged dry mole mixing ratio of $\left\langle\mathrm{CO}_{2}\right\rangle[\mathrm{ppm}]$,

$\left\langle\mathrm{CO}_{2}\right\rangle=\frac{\int\left[\mathrm{CO}_{2}\right] d p}{\int(1-q) d p}$,

where $p$ is the moist pressure, $q$ is the specific humidity, and $\left[\mathrm{CO}_{2}\right]$ is the molar mixing ratio of $\mathrm{CO}_{2}$ in parts per million (ppm). The quantity $\left\langle\mathrm{CO}_{2}\right\rangle$ is the mass of $\mathrm{CO}_{2}$ in a column normalized by the mass of dry air in the column and as such removes the variation due to topography. We carry separately the tracers $\left\langle\mathrm{CO}_{2}\right\rangle_{\text {bio }},\left\langle\mathrm{CO}_{2}\right\rangle_{\text {ocn }}$, and $\left\langle\mathrm{CO}_{2}\right\rangle_{\text {fossil }}$ associated with $\mathrm{CO}_{2}$ fluxes from the land biosphere, from the

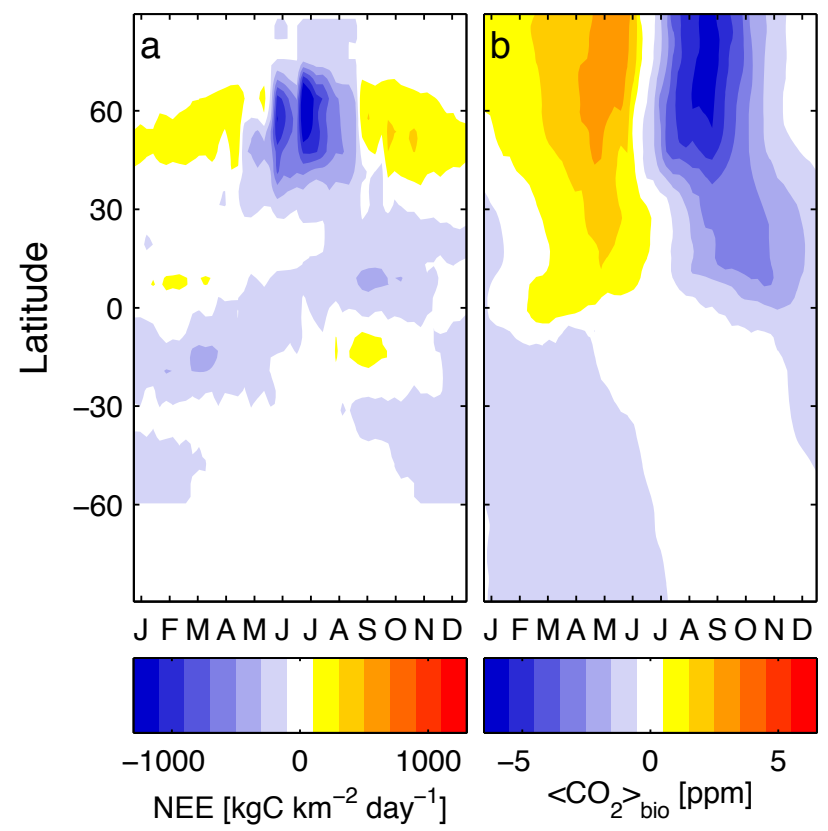

Fig. 1. (a) Net ecosystem exchange (NEE) as a function of latitude and month of the year. Strong temporal and spatial gradients in NEE characterize the Northern Hemisphere. Gradients are weaker in the tropics and Southern Hemisphere. The resulting $\left\langle\mathrm{CO}_{2}\right\rangle_{\text {bio }}$ is shown in (b). $\left\langle\mathrm{CO}_{2}\right\rangle_{\text {bio }}$ has accordingly stronger spatial and temporal gradients in the Northern Hemisphere, and these gradients are stronger during summer than winter.

oceans, and from fossil fuels. We sum these three components to determine $\left\langle\mathrm{CO}_{2}\right\rangle$.

AM2 has not been used extensively in tracer transport studies (Parrington et al., 2009). To evaluate its performance, we compare $\left\langle\mathrm{CO}_{2}\right\rangle$ fields from AM2 with $\left\langle\mathrm{CO}_{2}\right\rangle$ generated with the TM5 tracer transport model underlying CarbonTracker using identical fluxes. NOAA's CarbonTracker is a reanalysis product that uses near surface $\mathrm{CO}_{2}$ observations to optimize flux estimates for the biosphere and the ocean. We use CarbonTracker (version 2009) optimized biospheric and ocean fluxes and prescribed fossil fuel and biomass burning modules to generate $\left\langle\mathrm{CO}_{2}\right\rangle$ with AM2 and compare to the CarbonTracker output (Peters et al., 2007). We find that $\left\langle\mathrm{CO}_{2}\right\rangle$ is statistically similar between the two models, and that the use of AM2 introduces no bias relative to TM5. More details are provided in the results section.

Although AM2 has relatively poor vertical resolution above the tropopause, simulated distributions of stratospheric $\left[\mathrm{CO}_{2}\right]$ seem reasonable compared to available data. We compare seasonal patterns in upper tropospheric-lower stratospheric $\left[\mathrm{CO}_{2}\right]$ against data obtained aboard commercial aircraft travelling between Europe and Japan (Sawa et al., 2008). Seasonal patterns (as plotted in Sawa et al. (2008), Fig. 7) are captured qualitatively by AM2, and both meridional and vertical contrasts in AM2 $\left[\mathrm{CO}_{2}\right]$ are generally 


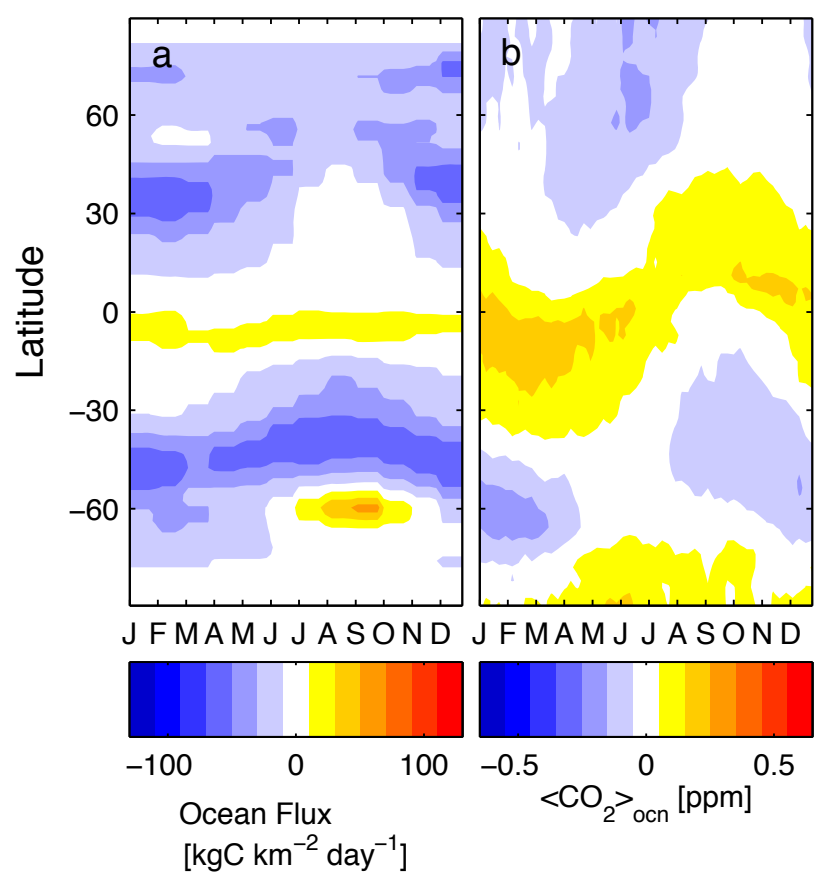

Fig. 2. (a) Ocean exchange as a function of latitude and month of the year. The scale has been reduced by a factor of 10 compared to NEE (Fig. 1), as ocean fluxes are smaller. (b) $\left\langle\mathrm{CO}_{2}\right\rangle_{\text {ocn }}$ resulting from ocean exchange.

within $\sim 20 \%$ of the observed contrasts of up to $5 \mathrm{ppm}$ across the tropopause. Given that the stratosphere only represents $\sim 15-20 \%$ of the midlatitude atmospheric column mass, this represents sufficient agreement for our purposes.

In this paper, we show both global $\left\langle\mathrm{CO}_{2}\right\rangle$ fields and $\left\langle\mathrm{CO}_{2}\right\rangle$ sampled from the model at locations that are part of the Total Carbon Column Observing Network (TCCON). TCCON is a network of ground-based Fourier transform spectrometers that obtain direct solar absorption spectra in the near infrared (Washenfelder et al., 2006). $\left\langle\mathrm{CO}_{2}\right\rangle$ is retrieved from these spectra, and the data are used both as validation for satellites and as independent data sets that, although spatially sparse, are temporally dense. In a subsequent paper, we compare the model output presented here with the data from six TCCON sites (Table 1).

\section{Results}

\subsection{Sources of $\left\langle\mathrm{CO}_{2}\right\rangle$ variations}

On multi-year time scales, fossil fuel emissions determine the interhemispheric $\left\langle\mathrm{CO}_{2}\right\rangle$ gradient. The impact of fossil fuel emissions on the north-south $\left\langle\mathrm{CO}_{2}\right\rangle$ gradient is seen in Fig. 3a, which shows a map of global $\left\langle\mathrm{CO}_{2}\right\rangle_{\text {fossil }}$, averaged over August with the global mean removed. Fossil fuel emissions occur largely in the Northern Hemisphere, where the bulk of the global population and land are located (Andres

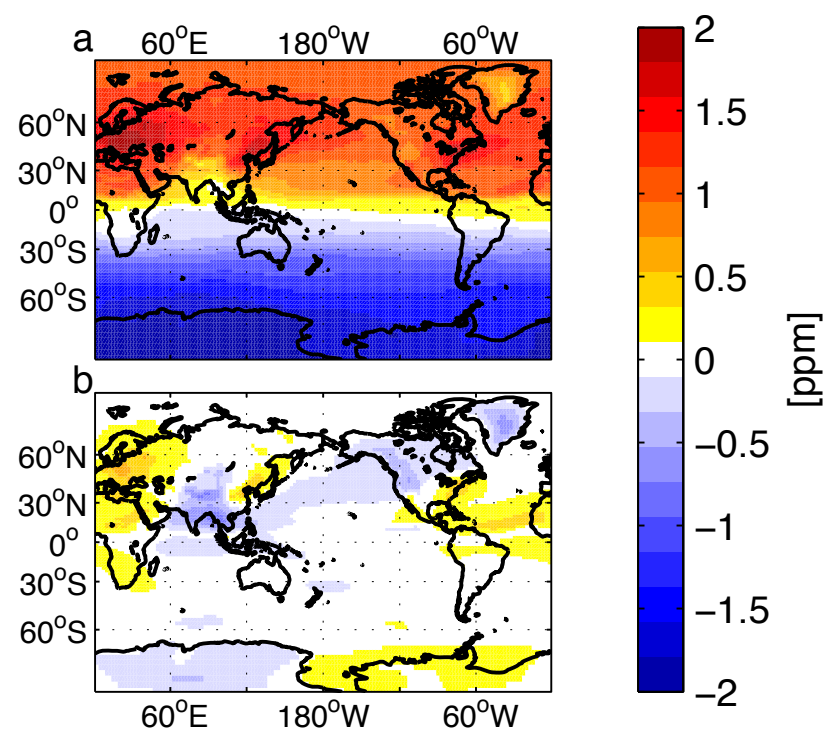

Fig. 3. (a) August $\left\langle\mathrm{CO}_{2}\right\rangle_{\text {fossil }}$ with global mean removed. Because the bulk of emissions occurs in the north, mean $\left\langle\mathrm{CO}_{2}\right\rangle_{\text {fossil }}$ is $2 \mathrm{ppm}$ higher in the Northern Hemisphere than in the Southern Hemisphere. (b) Deviation of August $\left\langle\mathrm{CO}_{2}\right\rangle_{\text {fossil }}$ from the zonal mean at each latitude. Contrasts in $\left\langle\mathrm{CO}_{2}\right\rangle_{\text {fossil }}$ between emission regions (e.g., eastern United States, Europe, and China) and upwind regions are less than $1 \mathrm{ppm}$. Overall, the meridional gradients are stronger than the zonal gradients.

et al., 1996). Mean $\left\langle\mathrm{CO}_{2}\right\rangle_{\text {fossil }}$ is higher by $2 \mathrm{ppm}$ in the Northern Hemisphere than in the Southern Hemisphere, with a pole-to-pole gradient of $\sim 4 \mathrm{ppm}$. Although we use 1990 fossil fuel fluxes in AM2, the observed gradient in the early 1990s may have been smaller, likely due to net uptake by the biosphere, which is ignored here (Ciais et al., 1995). On yearly timescales, not all $\mathrm{CO}_{2}$ emitted to the atmosphere by fossil fuel burning remains airborne: approximately 40-50\% is taken up by natural oceanic or terrestrial sinks (Le Quéré et al., 2009). Inference of the strength and location of these natural sinks is the focus of many inverse studies (Gurney et al., 2002, 2004).

Within the Northern Hemisphere, variations in the terrestrial biospheric fluxes largely determine the patterns of $\left\langle\mathrm{CO}_{2}\right\rangle$ variability. Figure $1 \mathrm{~b}$ shows a Hovmöller diagram (Hovmöller, 1949) of $\left\langle\mathrm{CO}_{2}\right\rangle_{\text {bio }}$ resulting from the fluxes shown in Fig. 1a. During winter and spring, Northern Hemisphere $\left\langle\mathrm{CO}_{2}\right\rangle_{\text {bio }}$ decreases from north to south. The gradient is generally small $(<2 \mathrm{ppm})$ from equator to pole; it reaches a maximum in late spring of $\sim 3 \mathrm{ppm}$. At the beginning of the summer, the north-south gradient of $\left\langle\mathrm{CO}_{2}\right\rangle_{\text {bio }}$ rapidly reverses, and hemispheric mean $\left\langle\mathrm{CO}_{2}\right\rangle_{\text {bio }}$ decreases as net respiration in the Northern Hemisphere transitions to net uptake. Such a signal is largely missing in the Southern Hemisphere as, outside the tropics, there is little landmass. The Northern Hemisphere shows the strongest gradients in $\left\langle\mathrm{CO}_{2}\right\rangle_{\text {bio }}$ during summer when the biosphere is most 
Table 1. TCCON sites sampled in AM2. Site locations are listed, as well as the seasonal cycle amplitude (SCA) from AM2 and TM5 when CarbonTracker year 2008 fluxes underlie the two models.

\begin{tabular}{lllcc}
\hline Site & Lat. & Lon. & AM2 SCA (ppm) & TM5 SCA (ppm) \\
\hline Bialystok, Poland & $53^{\circ} \mathrm{N}$ & $23^{\circ} \mathrm{E}$ & 8.3 & 8.2 \\
Orleans, France & $48^{\circ} \mathrm{N}$ & $2^{\circ} \mathrm{E}$ & 6.5 & 7.5 \\
Park Falls, Wisconsin, US & $45^{\circ} \mathrm{N}$ & $90^{\circ} \mathrm{W}$ & 7.8 & 8.1 \\
Lamont, Oklahoma, US & $37^{\circ} \mathrm{N}$ & $97^{\circ} \mathrm{W}$ & 5.8 & 5.7 \\
Pasadena, California, US & $34^{\circ} \mathrm{N}$ & $118^{\circ} \mathrm{W}$ & 4.7 & 4.9 \\
Lauder, New Zealand & $45^{\circ} \mathrm{S}$ & $170^{\circ} \mathrm{E}$ & 1.0 & 0.7 \\
\hline
\end{tabular}

active. In August and September, meridional gradients are at least twice as large in the zonal mean than outside the growing season. Southern Hemisphere $\left\langle\mathrm{CO}_{2}\right\rangle_{\text {bio }}$ is anti-correlated with Northern Hemisphere $\left\langle\mathrm{CO}_{2}\right\rangle_{\text {bio }}$, with low values in the Northern Hemisphere winter and high values in the Northern Hemisphere summer. The amplitude of seasonal $\left\langle\mathrm{CO}_{2}\right\rangle_{\text {bio }}$ variations is smaller throughout the Southern Hemisphere, and equator-pole gradients are very weak.

Figure $2 \mathrm{~b}$ shows the Hovmöller diagram for $\left\langle\mathrm{CO}_{2}\right\rangle_{\text {ocn }}$. Net ocean fluxes (Fig. 2a) are an order of magnitude smaller than land biosphere fluxes, and yield correspondingly smaller gradients (Fig. 2b) (Nevison et al., 2008). The seasonality in $\left\langle\mathrm{CO}_{2}\right\rangle_{\text {ocn }}$ is phase-shifted compared with $\left\langle\mathrm{CO}_{2}\right\rangle_{\text {bio }}$.

Local fluxes are manifest as temporal variations in $\left\langle\mathrm{CO}_{2}\right\rangle$ on short timescales. Shown in Fig. 4 are $\left\langle\mathrm{CO}_{2}\right\rangle_{\text {bio }}$ timeseries for the first two weeks of June and December. Diurnal patterns in $\left\langle\mathrm{CO}_{2}\right\rangle_{\text {bio }}$ vary among the Northern Hemisphere gridboxes shown: a tropical forest in southern Venezuela, a midlatitude mixed forest near Park Falls, Wisconsin, and a boreal forest near Poker Flats, Alaska. These sites have been chosen to illustrate differences in $\left\langle\mathrm{CO}_{2}\right\rangle$ at forested sites at different latitudes within the Northern Hemisphere. In June, the diurnal cycle is the most notable signature in tropical $\left\langle\mathrm{CO}_{2}\right\rangle_{\text {bio }}$ (Fig. 4a). Carbon is taken up by photosynthesis during the day and is respired at night, producing a peak-to-trough diurnal amplitude of $\sim 0.5 \mathrm{ppm}$. In midlatitudes (Fig. $4 \mathrm{~b}$ ), the diurnally varying flux forces a peak-to-trough diurnal amplitude of $\sim 0.5-0.75 \mathrm{ppm}$. The diurnal cycle in $\left\langle\mathrm{CO}_{2}\right\rangle_{\text {bio }}$ at the high latitude site is less clear during the summer growing season (Fig. 4c). Due to the long day and short night at high latitudes, photosynthetic uptake of carbon occurs over a greater fraction of the day. Outside the tropics, carbon taken up during the day is not in close balance with carbon respired, and a larger net drawdown is evident at high latitudes and midlatitudes over this two-week period. The diurnal cycle is similar in both winter and summer in the tropics because the biosphere experiences neither seasonal temperature nor sunlight limitation (Fig. 4d). At middle and high latitues, little or no diurnal signal is present during the winter, because respiration dominates total NEE both day and night (Fig. 4e-f). Rather, the variations in these timeseries occur on multi-day timescales, with changes in $\left\langle\mathrm{CO}_{2}\right\rangle_{\text {bio }}$ of order $1 \mathrm{ppm}$.

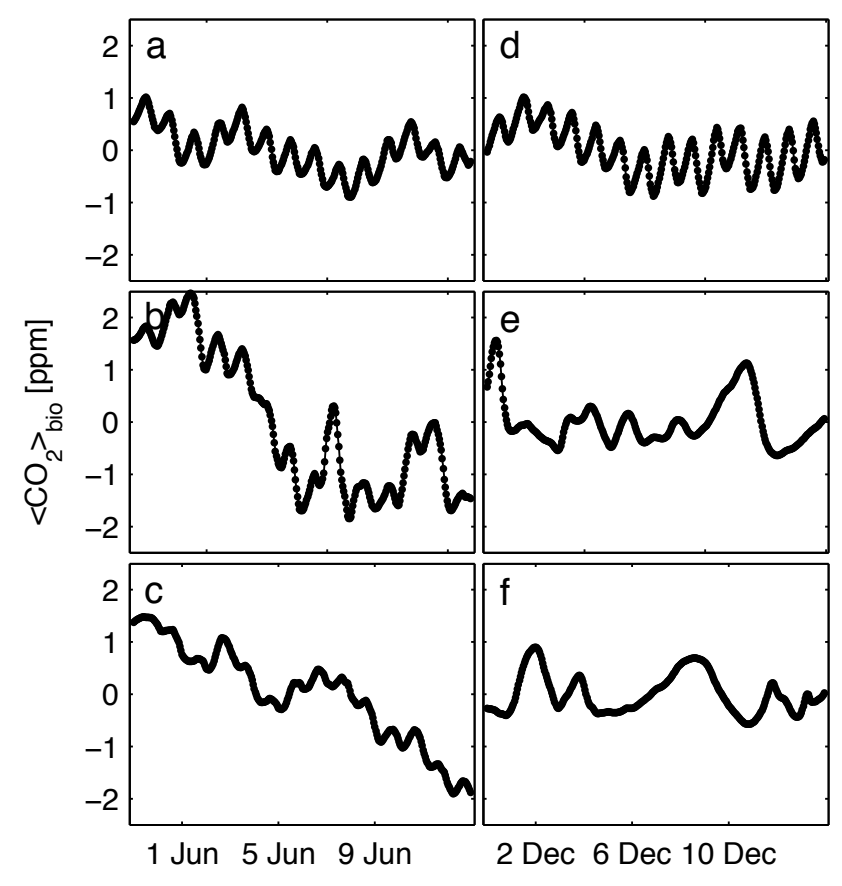

Fig. 4. Biospheric $\left\langle\mathrm{CO}_{2}\right\rangle_{\text {bio }}$ sampled at three Northern Hemisphere gridboxes in June (left) and December (right). (a, d) Tropical Venezuela $\left(3^{\circ} \mathrm{N}, 295^{\circ} \mathrm{E}\right)$. (b, e) Midlatitude $\left(46^{\circ} \mathrm{N}, 270^{\circ} \mathrm{E}\right)$. (c, f) High latitude Alaska $\left(65^{\circ} \mathrm{N}, 213^{\circ} \mathrm{E}\right)$. A diurnal cycle is evident at all sites during the summer, but it is dwarfed by synoptic-scale variability in mid- and high-latitudes. During the winter, only the tropical site shows a diurnal cycle in $\left\langle\mathrm{CO}_{2}\right\rangle_{\text {bio }}$.

Even during the middle of the growing season, only a small fraction of the variation in middle and high latitude $\left\langle\mathrm{CO}_{2}\right\rangle_{\text {bio }}$ is due to local fluxes. Figure 5 shows the relationship between flux and $\mathrm{CO}_{2}$ in the column at the midlatitude gridbox (Park Falls) for June. In Fig. 5, the difference in $\mathrm{CO}_{2}$ between the time with maximum concentration $(\sim 08: 00$ local time) and minimum concentration $(\sim 15: 00$ local time $)$ is plotted against the integrated flux for this seven-hour period. The change in $\left\langle\mathrm{CO}_{2}\right\rangle_{\text {bio }}$ shows a positive correlation with flux: greater uptake by the biosphere leads to drawdown in the column. The solid line in Fig. 5 represents the change 


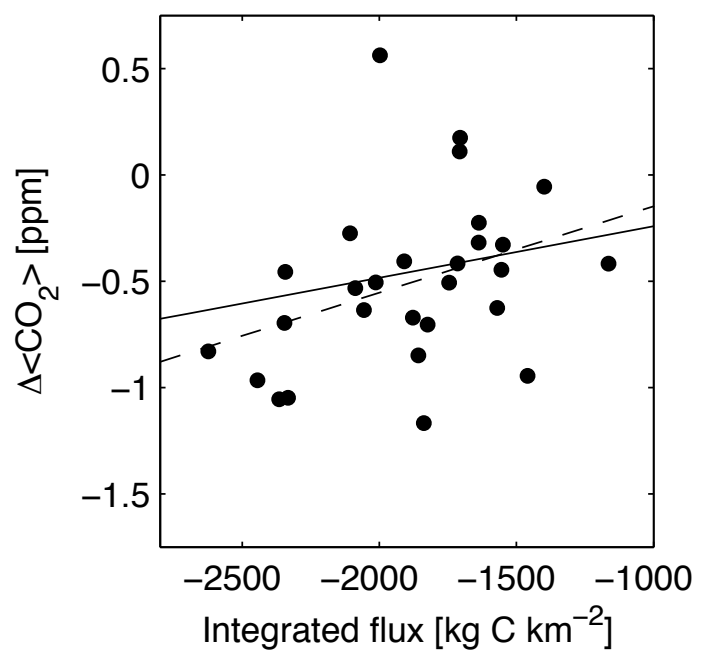

Fig. 5. Relationship between daytime $\Delta\left\langle\mathrm{CO}_{2}\right\rangle_{\text {bio }}$ (15:00 minus 08:00) and daytime NEE at the gridbox corresponding to Park Falls, Wisconsin in June. The dashed line represents the best fit to the data, but it accounts for only $12 \%$ of the variance (as determined by $R^{2}$ ). The solid line represents the change expected in $\left\langle\mathrm{CO}_{2}\right\rangle$ due to the surface flux alone.

expected in the column due to flux alone in the absence of horizontal transport. The dashed line in Fig. 5 represents the least squares fit to the data. It accounts for only $12 \%$ of the variance. Simulations that include only biospheric exchange for the gridboxes neighboring Park Falls confirm the small influence of local fluxes; the diurnal cycle at the peak of the growing season is $0.5-0.7 \mathrm{ppm}$, and local fluxes account for $20 \%$ of the variance in $\left\langle\mathrm{CO}_{2}\right\rangle$ during the day, confirming that even on short time scales, other factors are more important for $\left\langle\mathrm{CO}_{2}\right\rangle_{\text {bio }}$ variability. Flux estimation from column data is complicated by the large footprint of sources and sinks affecting $\left\langle\mathrm{CO}_{2}\right\rangle$. At $500 \mathrm{hPa}$, the center of mass of the column, westerly winds in the midlatitudes average $8.5 \mathrm{~m} \mathrm{~s}^{-1}$ during June. Thus, over the seven-hour period used to calculate $\Delta\left\langle\mathrm{CO}_{2}\right\rangle_{\text {bio }}$ in Fig. 5, the column is influenced by air originating more than $200 \mathrm{~km}$ upstream. Without spatial gradients in $\left\langle\mathrm{CO}_{2}\right\rangle$, this advection would have a much less pronounced influence on variability. In the presence of regional gradients, however, transport induces substantial temporal variability in $\left\langle\mathrm{CO}_{2}\right\rangle$. A simulation with labeled $\mathrm{CO}_{2}$ from local NEE shows that the the diurnal cycle due to local fluxes is between $0.5-0.75 \mathrm{ppm}$, and that intra-day differences in June are quite small (less than $0.1 \mathrm{ppm}$ ).

Regional fluxes can have a persistent effect on the column. The large-scale influence of regional fluxes is demonstrated through a relatively simple example: seasonally stationary fossil fuel emissions. Because fossil fuel fluxes are somewhat localized and steady (i.e., of one sign), $\left\langle\mathrm{CO}_{2}\right\rangle_{\text {fossil }}$ has a distinct regional signature. In Fig. 3b, we remove the zonal mean at each latitude to reveal these regional signatures. There is contrast in $\left\langle\mathrm{CO}_{2}\right\rangle_{\text {fossil }}$ between emission re-

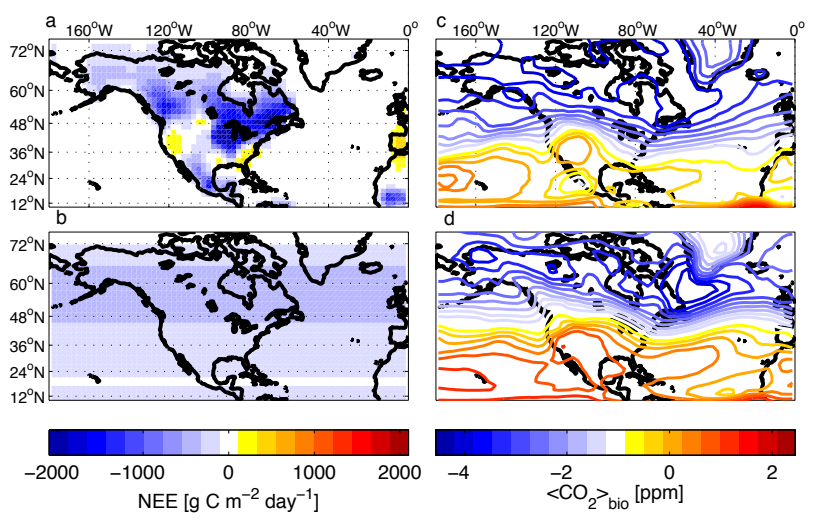

Fig. 6. (a) August-mean NEE from the CASA model. Fluxes over the ocean are zero, and land fluxes are generally negative, indicating uptake of carbon by the terrestrial biosphere. (b) Zonal mean August NEE. Fluxes over land and ocean at a given latitude are the same, and there are only weak north-south gradients in fluxes over the Northern Hemisphere. Nonetheless, gradients in $\left\langle\mathrm{CO}_{2}\right\rangle_{\text {bio }}$ are similar for both distributions of underlying surface fluxes (c and $\mathbf{d}$ ).

gions, such as Europe and East Asia, and their upwind counterparts. The mean residence time of fossil $\mathrm{CO}_{2}$ within $\sim 30^{\circ}$ longitude of emission is only 3-4 days, so these zonal gradients do not exceed $0.5 \mathrm{ppm}$ even when the flux is rather large (e.g., Eastern US). The regional signature of fossil fuel fluxes is, however, proportional to the strength of the flux as expected for the linearity of passive tracer advection; in simulations with doubled fossil fuel emissions, the regional contrasts also double.

In the Northern Hemisphere, spatial gradients in $\left\langle\mathrm{CO}_{2}\right\rangle$ are largely determined by the land biosphere fluxes. Unlike for the fossil fuel emissions, biospheric fluxes are sufficiently diffuse that even in the middle of the growing season, the regional pattern of $\left\langle\mathrm{CO}_{2}\right\rangle$ has little to do with the regional biospheric fluxes. Rather, the pattern in $\left\langle\mathrm{CO}_{2}\right\rangle$ reflects the north-south gradient in the fluxes acted upon by the large-scale dynamics. To illustrate, we redistribute the standard CASA fluxes (shown for August in Fig. 6a) uniformly around latitude bands (Fig. 6b). Thus, both simulations have the same north-south flux gradient in the zonal mean. The resulting August-mean $\left\langle\mathrm{CO}_{2}\right\rangle$ distributions are shown in Fig. $6 \mathrm{c}$ and d. The patterns of $\left\langle\mathrm{CO}_{2}\right\rangle$ variability in the two simulations are quite similar; averaged over August, fewer than $50 \%$ of Northern Hemisphere gridboxes show a difference greater than $1 \mathrm{ppm}$ between the simulations with CASA fluxes and those with zonally uniform fluxes, and fewer than $10 \%$ show a difference greater than 2 ppm (Fig. 7). The pattern of $\left\langle\mathrm{CO}_{2}\right\rangle$, even over the center of the growing region of North America, is largely a manifestation of the northsouth gradient in the zonally averaged flux. Local maxima (e.g., southern California) and minima (e.g., midwestern US) in the CASA simulations do not reflect the strength of the underlying sources and sinks but result from the interaction 


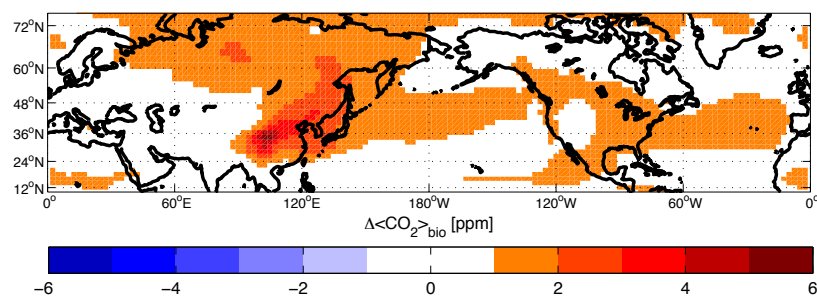

Fig. 7. Difference plot for August $\left\langle\mathrm{CO}_{2}\right\rangle_{\text {bio }}$ resulting from zonalmean NEE versus CASA NEE (i.e., Fig. 6d minus Fig. 6c). $\Delta\left\langle\mathrm{CO}_{2}\right\rangle_{\text {bio }}$ is generally smaller than $2 \mathrm{ppm}$ and exhibits a positive anomaly downwind of land uptake regions. Northern hemispheric summer $\mathrm{CO}_{2}$ increases by $\sim 0.1 \%$ in the simulation with zonal fluxes compared to the simulation with CASA fluxes.

Table 2. Scale factors used to increase Northern Hemisphere net primary productivity (NPP) by $25 \%$ in CASA.

\begin{tabular}{lccr}
\hline $\begin{array}{l}\text { Latitude } \\
\text { range }\end{array}$ & $\begin{array}{c}\text { Annual } \\
\text { NPP [Pg C] }\end{array}$ & $\begin{array}{c}\text { Weighting } \\
\text { factor }\end{array}$ & $\begin{array}{r}\text { \% Increase } \\
\text { to NEE }\end{array}$ \\
\hline $15-20$ & 1.66 & 4.25 & 5 \\
$20-30$ & 3.08 & 2.80 & 3 \\
$30-40$ & 4.10 & 2.30 & 3 \\
$40-50$ & 5.63 & 1.95 & 10 \\
$50-60$ & 4.78 & 2.15 & 41 \\
$60-70$ & 2.21 & 3.45 & 98 \\
\hline
\end{tabular}

of climatological stationary waves and the large-scale northsouth differences in biospheric carbon uptake.

The north-south distribution of surface fluxes also dominates the seasonal variations in $\left\langle\mathrm{CO}_{2}\right\rangle$. We calculate the peak-to-trough seasonal cycle amplitude in $\left\langle\mathrm{CO}_{2}\right\rangle$ to estimate temporal variations at five Northern Hemisphere TC$\mathrm{CON}$ sites. The Northern Hemisphere $\left\langle\mathrm{CO}_{2}\right\rangle$ timeseries have been detrended by subtracting the Southern Hemisphere $\left\langle\mathrm{CO}_{2}\right\rangle$ trend from the gridbox corresponding to Lauder, New Zealand. The seasonal cycle amplitude (the difference between the maximum and minimum of the monthly mean $\left.\left\langle\mathrm{CO}_{2}\right\rangle\right)$ changes little when zonally averaged biospheric fluxes are used. The seasonal cycle amplitude at the gridbox corresponding to Park Falls, for example, is reduced by less than $20 \%$ in simulations with zonal fluxes rather than CASA fluxes. The seasonal cycle amplitudes at other midlatitude sites change by less than $15 \%$, and at the subtropical sites, by less than $5 \%$, when zonally symmetric biospheric fluxes are used. To further test the response of the seasonal cycle amplitude to perturbations in surface fluxes, we uniformly scale NEE across the Northern Hemisphere by factors between one and two. Figure 8a shows that the seasonal cycle amplitudes at all five TCCON sites scale linearly with NEE.

To probe the signature of a regional flux increase on $\left\langle\mathrm{CO}_{2}\right\rangle_{\text {bio }}$ at various latitudes, we amplify NEE in $10^{\circ}$ lati-

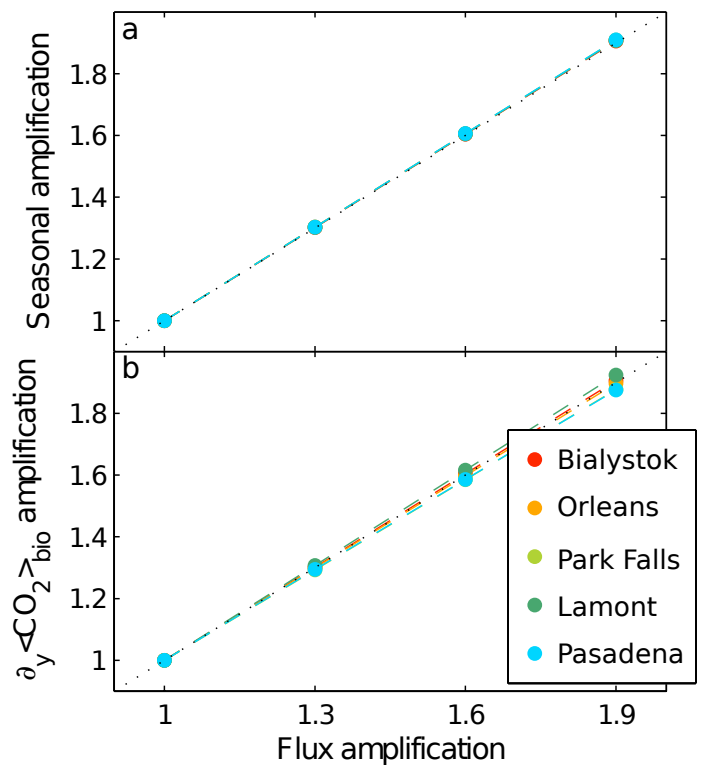

Fig. 8. (a) Amplification to the seasonal cycle amplitude in simulations with amplified NEE versus CASA NEE. Scaling NEE throughout the Northern Hemisphere increases the seasonal cycle amplitude proportionally at each of five Northern Hemisphere TCCON sites. (b) Amplification to the estimated gradients in simulations with amplified NEE versus CASA NEE. The estimated $\left\langle\mathrm{CO}_{2}\right\rangle_{\text {bio }}$ gradient, $\partial_{y} \widehat{\left\langle\mathrm{CO}_{2}\right\rangle}$ bio, also increases proportionally at each of the TCCON sites. The unit diagonal is plotted in each panel. Site acronyms are defined in Table 1.

tude bands. We scale NEE in each band by an amount that increases Northern Hemisphere NPP by $25 \%$ (Table 2). Because NEE in our model is the residual of NPP and respiration at three-hourly intervals, a uniform increase in NPP increases NEE at high latitudes, where there is a large seasonality in NEE, but has little effect at low latitudes where NPP is in balance with respiration on short time scales. Figure 9 shows the relative increase of the seasonal cycle amplitude in $\left\langle\mathrm{CO}_{2}\right\rangle_{\text {bio }}$ at Northern Hemisphere TCCON sites as a function of the latitude of amplification. In general, the seasonal cycle amplitude increases as fluxes are amplified further north, due to the greater seasonality of NEE at higher latitudes. Except for Pasadena, California $\left(34^{\circ} \mathrm{N}\right)$, the sites show little sensitivity to an increase in subtropical fluxes. Although Pasadena shows the largest response among all sites to flux amplification south of $30^{\circ} \mathrm{N}$, its seasonal cycle amplitude changes more (30\% compared to $15 \%$ ) when fluxes are amplified north of $50^{\circ}$. Lamont, Oklahoma, which also sits on the edge of the subtropics $\left(36^{\circ} \mathrm{N}\right)$, shows a step function increase in seasonal cycle amplitude as enhanced exchange moves north of the subtropical jet: the seasonal cycle amplitude is essentially unaffected by changes in flux south of $30^{\circ}$, but it increases by a uniform $30 \%$ when fluxes are enhanced north of $40^{\circ}$. The seasonal cycle amplitude at Park Falls, located in the center of a biospherically active region 


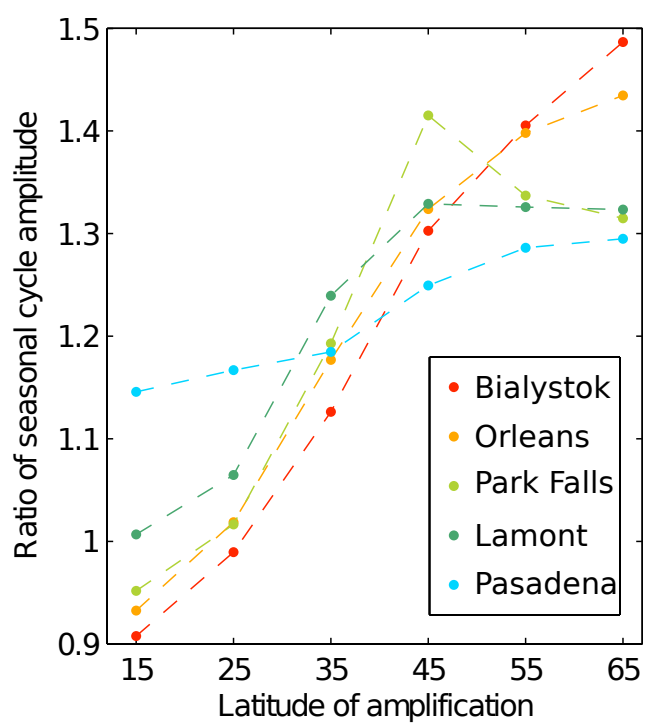

Fig. 9. Amplification in $\left\langle\mathrm{CO}_{2}\right\rangle_{\text {bio }}$ seasonal cycle amplitude when NEE is enhanced in $10^{\circ}$ latitude bands relative to CASA NEE. The seasonal cycle amplitude from simulations with enhanced NEE is normalized by the corresponding seasonal cycle amplitude resulting from CASA fluxes. The seasonal cycle amplitude is more sensitive to flux enhancements in boreal ecosystems, due to the greater seasonality of NEE.

$\left(46^{\circ} \mathrm{N}\right)$, peaks when amplification impacts local fluxes between $40-50^{\circ}$. However, the seasonal cycle amplitude at European sites $\left(48^{\circ}\right.$ and $\left.53^{\circ} \mathrm{N}\right)$ increase monotonically as fluxes increase to their north. These diverse responses highlight the sensitivity of the seasonal cycle amplitude to remote fluxes. Enhancing the seasonal cycle in NEE at high latitudes has a significant impact on the atmospheric signal thousands of kilometers away. These results, together with the fact that seasonal cycle amplitude scales linearly with total Northern Hemisphere fluxes, confirm that hemispheric-scale fluxes determine the seasonal cycle amplitude in the column (Yang et al., 2007).

\subsection{Synoptic-scale variations and relation to gradients}

Synoptic variations in $\left\langle\mathrm{CO}_{2}\right\rangle$ are intimately tied to the largescale gradients. Because $\left\langle\mathrm{CO}_{2}\right\rangle$ fields are strongly influenced by the interaction between fluxes and large-scale dynamics, we use a dynamic coordinate to diagnose the influence of synoptic activity. We analyze the relationship between meridional gradients in $\left\langle\mathrm{CO}_{2}\right\rangle$ and synoptic scale variability by using an empirical relationship between variations in $\left\langle\mathrm{CO}_{2}\right\rangle$ and variations in potential temperature, $\theta$, which acts as a dynamical tracer of the latitude of origin of airmasses because $\theta$ is conserved following adiabatic flow. Near the surface, such flow is largely horizontal because vertical motion is inhibited. Latent heat release and boundary layer turbulence, however, can cause deviations from adiabaticity on large scales. We therefore choose $\theta$ near the surface but above the boundary layer, at $700 \mathrm{hPa}$, to define a meridional displacement scale,

$L=\frac{\theta^{\prime}-\bar{\theta}_{0}}{\partial_{y} \bar{\theta}}$,

where $\theta^{\prime}$ is the local potential temperature bandpass filtered to remove low-frequency (greater than 21 days) and highfrequency variability (less than 3 days), thus isolating synoptic variations. The reference value $\overline{\theta_{0}}$ represents monthly mean $\theta$ at a reference location (by default, the local gridbox). The gradient $\partial_{y} \bar{\theta}$ represents the monthly mean meridional gradient in $\theta$ smoothed by a radial Gaussian filter with standard deviation of $1500 \mathrm{~km}$. The displacement scale $L$ has units of length and can be interpreted as the mean meridional distance from the reference latitude from which an adiabatically transported air parcel originates. We can then infer an estimate of the $\left\langle\mathrm{CO}_{2}\right\rangle$ gradient using variations in $\left\langle\mathrm{CO}_{2}\right\rangle$ :

$\left.\partial_{y} \widehat{\left\langle\mathrm{CO}_{2}\right.}\right\rangle=\frac{\left\langle\mathrm{CO}_{2}\right\rangle^{\prime}}{L}$.

Here, $\left\langle\mathrm{CO}_{2}\right\rangle^{\prime}$ represents the 3-21 day bandpass filtered $\left\langle\mathrm{CO}_{2}\right\rangle$. The bandpass filtering isolates the synoptic variations that are well resolved in GCMs. It makes it possible to compare our results with actual data, in which small-scale, high-frequency variations that may not be well resolved in GCMs also contribute to fluctuations, particularly of passive tracers such as $\mathrm{CO}_{2}$, which have a relatively flat spectrum as a function of length scale.

The gradient estimated from variations in $\left\langle\mathrm{CO}_{2}\right\rangle$, $\partial_{y} \widehat{\left\langle\mathrm{CO}_{2}\right\rangle}$, approximates the north-south gradient in the midlatitudes. In Fig. 10a, we plot the August $\left\langle\mathrm{CO}_{2}\right\rangle$ gradient estimated using Eq. (3), while in Fig. 10b, we plot the gradient obtained directly from AM2 $\left\langle\mathrm{CO}_{2}\right\rangle$, smoothed using the $1500 \mathrm{~km}$ radial filter. Thus, covariations in observed $\left\langle\mathrm{CO}_{2}\right\rangle$ and $\theta$ can be used to infer the large-scale north-south gradient in $\left\langle\mathrm{CO}_{2}\right\rangle$, provided that data are obtained in a region with sufficient synoptic-scale turbulent activity (i.e., in midlatitudes). Outside the midlatitudes, Fig. 10 suggests that the method does not provide an accurate estimate of the large scale gradient as $\theta$ gradients are relatively small and eddy activity is weaker.

The large-scale north-south gradient can thus be constrained from variations within a single timeseries. We estimate the mean $30-60^{\circ} \mathrm{N}\left\langle\mathrm{CO}_{2}\right\rangle$ contrast over North America in AM2 using Eq. (3) with $\left\langle\mathrm{CO}_{2}\right\rangle^{\prime}$ sampled at the gridbox corresponding to Park Falls and with the displacement $L$ determined from the potential temperature contrast between $30^{\circ} \mathrm{N}$ and $60^{\circ} \mathrm{N}$ (Eq. 2). Figure 11 compares the thus estimated $\left\langle\mathrm{CO}_{2}\right\rangle$ contrast to the contrast determined from taking the difference in $\left\langle\mathrm{CO}_{2}\right\rangle$ averaged over $180^{\circ}-300^{\circ} \mathrm{W}$ at $30^{\circ}$ and $60^{\circ}$. The two methods of determining the $\left\langle\mathrm{CO}_{2}\right\rangle$ contrast are in good agreement across seasons, confirming that quantitative information about the large-scale gradient is contained in synoptic variations at a single midlatitude site. 


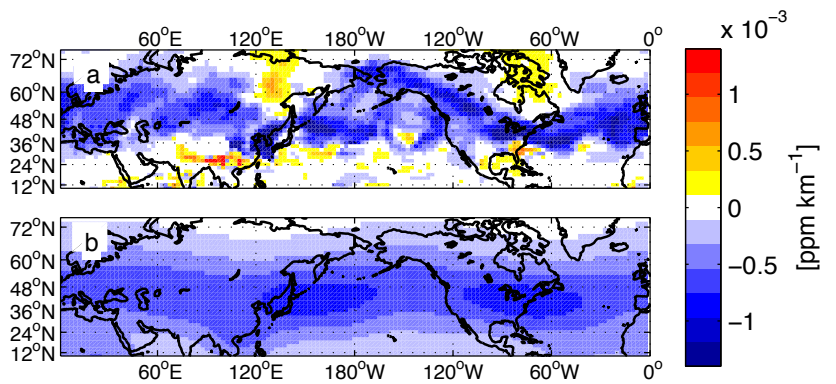

Fig. 10. August gradients in simulated $\left\langle\mathrm{CO}_{2}\right\rangle$. (a) Estimated gradient $\partial \widehat{\left.\partial \mathrm{CO}_{2}\right\rangle}$ calculated at each gridbox from variations in $\left\langle\mathrm{CO}_{2}\right\rangle$ and $\theta$. (b) Actual meridional gradient in $\left\langle\mathrm{CO}_{2}\right\rangle$ smoothed over $1500 \mathrm{~km}$.

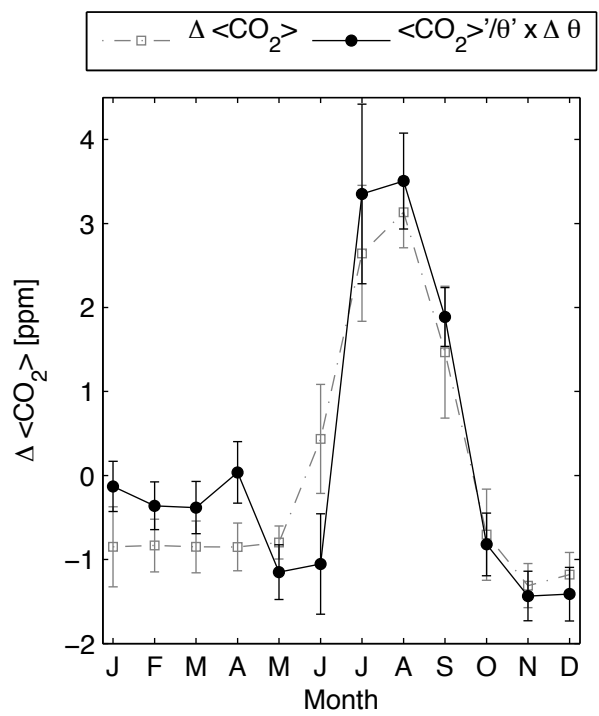

Fig. 11. $\left\langle\mathrm{CO}_{2}\right\rangle$ contrast between 30 and $60^{\circ} \mathrm{N}$ over North America (averaged between 180 and $300^{\circ} \mathrm{W}$ ). The gray squares are the actual contrast, while the black circles are the contrast calculated from variations in $\left\langle\mathrm{CO}_{2}\right\rangle$ and $\theta$.

Figure 12 shows that the correlation between variations in $\left\langle\mathrm{CO}_{2}\right\rangle$ and variations in $\theta$ reflects meridional gradients in $\left\langle\mathrm{CO}_{2}\right\rangle$ at Northern Hemisphere TCCON sites. Figure 12a shows the seasonal cycle in $\left\langle\mathrm{CO}_{2}\right\rangle$ for five TCCON sites in a simulation forced by zonal biospheric fluxes. The seasonal cycle amplitude is greater in midlatitudes than in the subtropics, and the summer minima in $\left\langle\mathrm{CO}_{2}\right\rangle$ are earlier. During the summer, the $\left\langle\mathrm{CO}_{2}\right\rangle$ contrast among sites grows, and the contrast decreases in winter. The dynamical connection between the sites is seen in the lower panels, where daily $\left\langle\mathrm{CO}_{2}\right\rangle^{\prime}$ in February, May, August, and November (corresponding to shaded periods in Fig. 12a) is plotted against the meridional displacement relative to Park Falls (i.e., $\overline{\theta_{0}}$ in Eq. (2) represents the monthly mean $\theta$ at the gridbox corresponding to Park Falls rather than at the local gridbox). A negative displacement represents southerly origin while a positive displacement represents northerly origin.

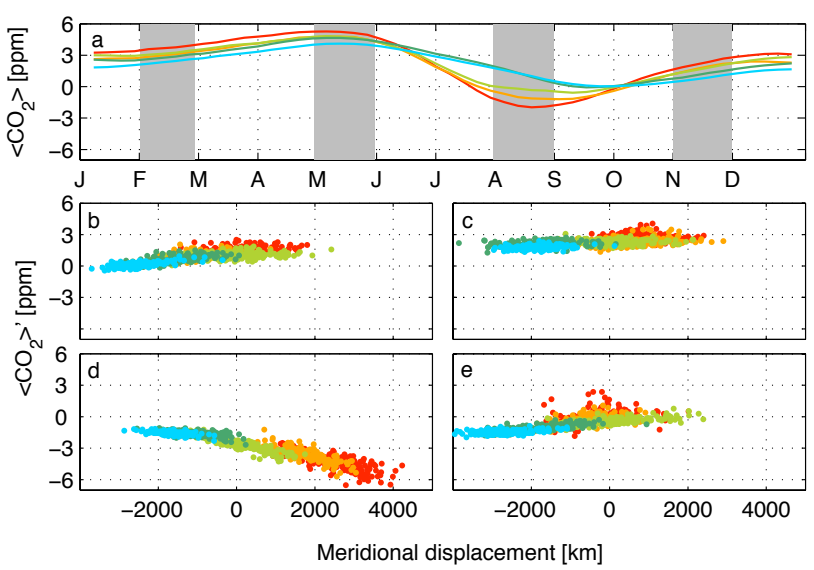

Fig. 12. (a) Detrended $\left\langle\mathrm{CO}_{2}\right\rangle$ for each of five TCCON sites sampled in AM2 driven by zonal-mean NEE. The data at each site have been detrended based on annual mean Southern Hemisphere data Shaded regions represent the months plotted in (b-e), which show bandpass filtered $\left\langle\mathrm{CO}_{2}\right\rangle$ plotted against the meridional displacement relative to Park Falls $\left(46^{\circ} \mathrm{N}\right)$, for four months: (b) February (c) May (d) August (e) November. Colors are the same as Figs. 8 and 9.

The range of $\left\langle\mathrm{CO}_{2}\right\rangle^{\prime}$ in Fig. 12b-e reflects the gradient in $\left\langle\mathrm{CO}_{2}\right\rangle$ at the sites. In general, outside the growing season, the $\left\langle\mathrm{CO}_{2}\right\rangle$ gradient is positive (higher to the north). During May, the gradient is essentially flat as the north-south $\left\langle\mathrm{CO}_{2}\right\rangle$ gradient reverses at the growing season onset at high latitudes (Fig. 1b). August data is plotted in Fig. 12d. During summer, the total $\left\langle\mathrm{CO}_{2}\right\rangle^{\prime}$ range is largest and the $\left\langle\mathrm{CO}_{2}\right\rangle$ gradient is negative because northern $\left\langle\mathrm{CO}_{2}\right\rangle$ has been drawn down by the biosphere. Figure $12 \mathrm{~b}-\mathrm{e}$ demonstrate how transport mixes $\left\langle\mathrm{CO}_{2}\right\rangle$ among the sites: there is a substantial overlap of $\left\langle\mathrm{CO}_{2}\right\rangle$ sampled at different sites along the meridional displacement curve.

\subsection{Relationship between synoptic scale variability and flux}

Like the seasonal cycle amplitude, $\widehat{\partial y\left\langle\mathrm{CO}_{2}\right\rangle}$ scales linearly with fluxes, and therefore linearly with the north-south gradient in the mid-latitudes. Figure $8 \mathrm{~b}$ shows the ratio of $\partial_{y}{\widehat{\left\langle\mathrm{CO}_{2}\right\rangle}}_{\text {bio }}$ for simulations with Northern Hemisphere amplified fluxes relative to CASA fluxes. With NEE amplified over a range of latitudes, $\partial_{y}{\widehat{\left\langle\mathrm{CO}_{2}\right\rangle}}_{\text {bio }}$ responds differently to amplification north or south of the storm track. Figure 13 shows $\partial_{y}{\widehat{\left\langle\mathrm{CO}_{2}\right\rangle}}_{\text {ioo }}$ at Park Falls for simulations with amplified NEE relative to those with CASA NEE. When flux amplification occurs between 10 and $50^{\circ}, \partial_{y}{\overline{\left\langle\mathrm{CO}_{2}\right\rangle}}_{\text {bio }}$ changes little. When flux amplification occurs north of $50^{\circ}$, however, the estimated gradient essentially doubles.

Diagnostics such as the seasonal cycle amplitude and $\partial \widehat{\partial_{y}\left\langle\mathrm{CO}_{2}\right\rangle}$ provide information about the large-scale distribution of the fluxes. We can also use them to attribute regional 


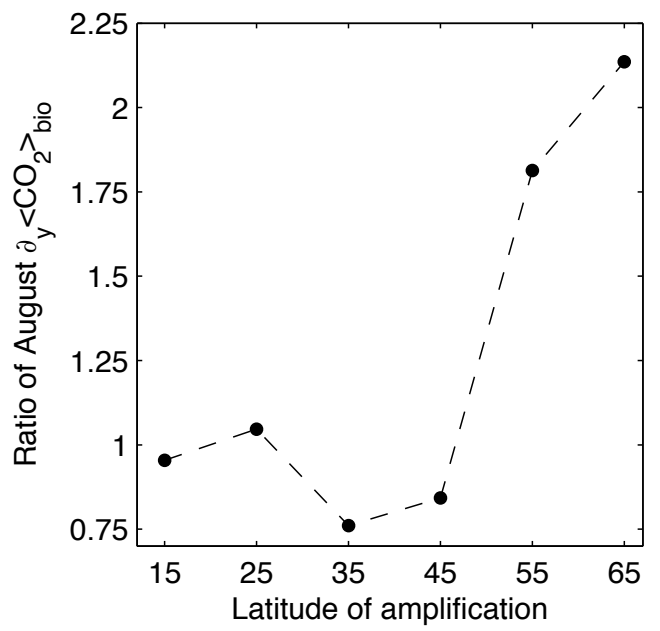

Fig. 13. August $\partial_{y} \widehat{\left\langle\mathrm{CO}_{2}\right\rangle}$ bio estimated at Park Falls, Wisconsin as NEE is amplified in the $10^{\circ}$ bands shown in Table 2 . The estimated gradient remains essentially the same when fluxes are amplified to the south of the site, whereas the gradient doubles when fluxes are amplified north of the site. Enhancing NEE north of the site draws down $\left\langle\mathrm{CO}_{2}\right\rangle$ during August, leading to a larger north-south gradient.

fluxes. Figure 14a shows the seasonal cycle for $\left\langle\mathrm{CO}_{2}\right\rangle$ at Northern Hemisphere TCCON sites in a simulation with CASA biospheric fluxes. May and August $\left\langle\mathrm{CO}_{2}\right\rangle^{\prime}$ from this simulation are plotted against meridional displacement relative to Park Falls in Fig. 15a. The TCCON sites do not fall along a smooth curve, as they did when zonal biospheric fluxes were used (Fig. 12c, d). During May, $\left\langle\mathrm{CO}_{2}\right\rangle$ sampled at the European sites is slightly lower than at North American sites due to earlier onset of the growing season, evident in the Fig. 14a timeseries. During August, the data sampled at Park Falls are offset about 2 ppm compared to the European sites, and compared to the simulation with zonal fluxes. Part of this offset $(\sim 0.5 \mathrm{ppm})$ is due to persistent influence of regional fossil emissions (Fig. 3b), and $\sim 1.5 \mathrm{ppm}$ is due to the regional biospheric drawdown in Park Falls (Fig. 7). These regional differences are not simply confined to the boundary layer, but also exist in the lower troposphere. At the three midlatitude TCCON sites, between 20 and $40 \%$ of the summer variability in Fig. 15a is explained by variability in the meridional displacement (as measured by the $R^{2}$ value). This fraction is smaller in the subtropics (15-20\% during the summer). During the winter months (not shown), total variability decreases, but the fraction explained by the meridional displacement is still $\sim 20 \%$ in the midlatitudes, and increases to $40-50 \%$ in the subtropics.

We present two sensitivity studies to demonstrate further the response of these diagnostics to regional changes in flux. In the first study, we amplify boreal exchange. In the second, we lengthen the boreal growing season. Based on a comparison of the seasonal cycle amplitude of $\left\langle\mathrm{CO}_{2}\right\rangle$ observed

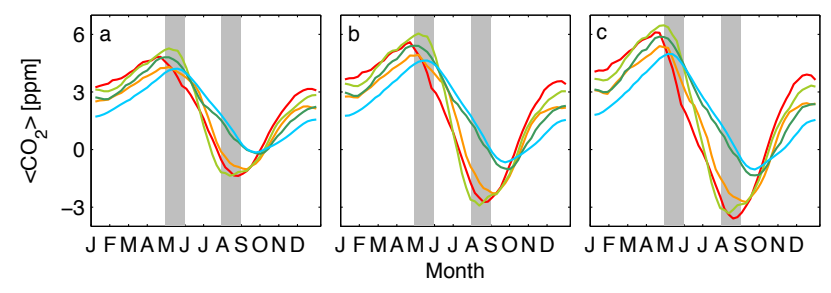

Fig. 14. Detrended $\left\langle\mathrm{CO}_{2}\right\rangle$ at TCCON sites in three simulations with different surface fluxes. (a) CASA fluxes. (b) Boreal fluxes enhanced. (c) Boreal fluxes enhanced with early onset of the growing season. When boreal fluxes are increased, the seasonal cycle amplitude increases. When the length of the growing season increases, the seasonal cycle amplitudes increase further despite no increase in net exchange between (b) and (c). Colors are the same as Figs. 8-9. Daily data from the shaded periods (May and August) are plotted in Fig. 15.

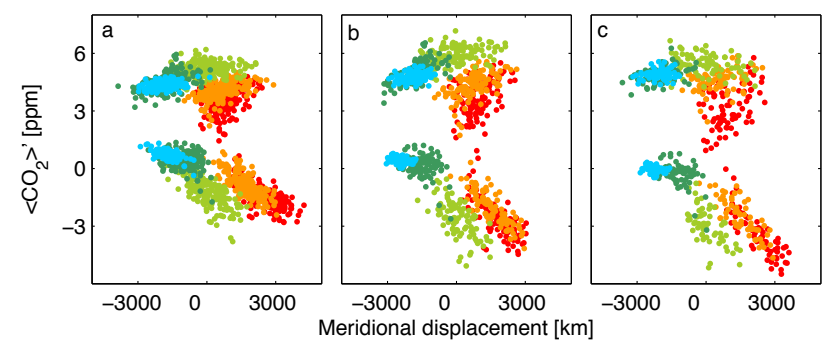

Fig. 15. Northern Hemisphere TCCON $\left\langle\mathrm{CO}_{2}\right\rangle^{\prime}$ plotted against meridional displacement (relative to Park Falls) for three simulations with perturbed surface fluxes. In each panel, the top cloud of points shows May data while the lower cloud of points shows August data. (a) CASA fluxes. (b) Boreal fluxes enhanced. (c) Boreal fluxes enhanced with early onset of the growing season.

at Park Falls with modeled $\left\langle\mathrm{CO}_{2}\right\rangle$, Yang et al. (2007) suggest that the Northern Hemisphere NEE is underestimated by $\sim 30 \%$. Given that the midlatitude seasonal cycle amplitude is insensitive to NEE amplification in the tropics (Fig. 9), we enhance boreal fluxes by $50 \%$ between 45 and $65^{\circ}$ to increase hemispheric NEE by $30 \%$. We plot the time traces in $\left\langle\mathrm{CO}_{2}\right\rangle$ sampled at TCCON sites in Fig. 14b. The seasonal cycle amplitudes of the northern sites increase by $\sim 25 \%$ and the gradient among the Northern Hemisphere sites grows during the summer (by $\sim 60 \%$ in Fig. 15b compared with Fig. 15a). The early drawdown in Europe in May is even more obvious when the northern uptake is greater (Fig. 15b) and the range of $\left\langle\mathrm{CO}_{2}\right\rangle^{\prime}$ increases during August.

The phasing of the growing season onset also is apparent in our diagnostics. Numerous studies have suggested that earlier spring warming leads to early onset of net flux into the ecosystem (Piao et al., 2008). We hasten the onset of the growing season in the simulation with enhanced boreal NEE between $50-60^{\circ} \mathrm{N}$ by one month. We add July NEE to May NEE (turning a net source into a net sink), and 


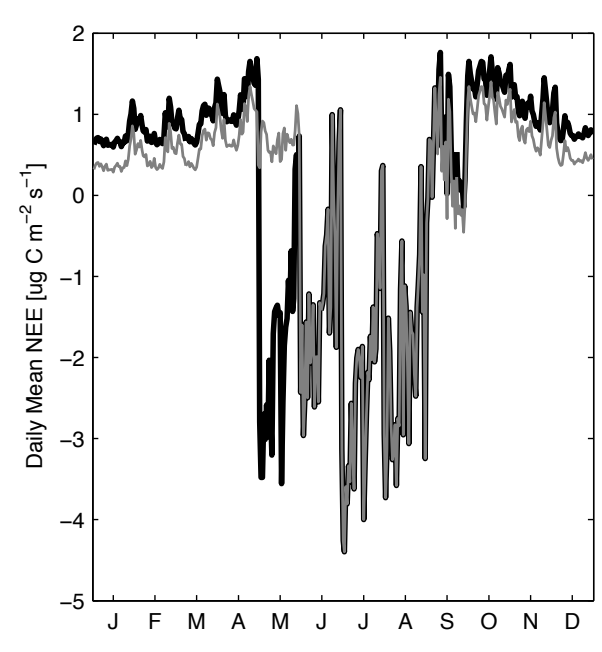

Fig. 16. Daily mean NEE at $270^{\circ} \mathrm{W}, 60^{\circ} \mathrm{N}$ for boreal-enhanced CASA fluxes (gray) and long boreal growing season (black). July NEE has been added to May to hasten the onset of the growing season in spring, and the net flux of carbon to the atmosphere is increased outside the growing season to balance the fluxes.

increase respiration across non-summer months (September to March) so that NEE is balanced annually. A timeseries of NEE for a representative location in boreal North America is shown in Fig. 16. With earlier onset of the growing season, the maximum $\left\langle\mathrm{CO}_{2}\right\rangle$ occurs at Bialystok three weeks earlier in spring, while the phasing of $\left\langle\mathrm{CO}_{2}\right\rangle$ at other sites is unaffected (Fig. 14c). The net effect of a longer growing season is stronger north-south gradients during the early summer and lower summer minima in $\left\langle\mathrm{CO}_{2}\right\rangle$ at the European sites such that the TCCON sites more clearly fall along a single $\left\langle\mathrm{CO}_{2}\right\rangle^{\prime}-L$ curve for August in this scenario (Fig. $15 \mathrm{c}$ ).

\subsection{Effect of model transport errors}

A further illustration of the role of large-scale flux patterns in determining the pattern in $\left\langle\mathrm{CO}_{2}\right\rangle$ is the small sensitivity of the fields to vertical mixing. We alter the vertical layer where carbon exchange in the model occurs. CASA biospheric fluxes were imposed at three different levels in the model, corresponding to the surface, $\sim 800 \mathrm{hPa}$ and $\sim 700 \mathrm{hPa}$, the latter being well in the free troposphere.

Overall, vertical mixing has a small effect on the mass gradient in $\left\langle\mathrm{CO}_{2}\right\rangle$. Figure 17 shows the difference in the monthly mean $30-60^{\circ} \mathrm{N}\left\langle\mathrm{CO}_{2}\right\rangle_{\text {bio }}$ contrast over North America between simulations with elevated and surface exchange. When surface exchange occurs at 800 or $700 \mathrm{hPa}$, the $\left\langle\mathrm{CO}_{2}\right\rangle_{\text {bio }}$ gradient induced by improper vertical mixing is less than $0.2 \mathrm{ppm}$ at all seasons. The fact that $\left\langle\mathrm{CO}_{2}\right\rangle$ is a mass constraint and that the footprint is inherently larger means that local fluxes and sub-gridscale physics have minimal influence on gradients. Even with a gross error in vertical mixing, the large-scale diagnostics in $\left\langle\mathrm{CO}_{2}\right\rangle$ change little.

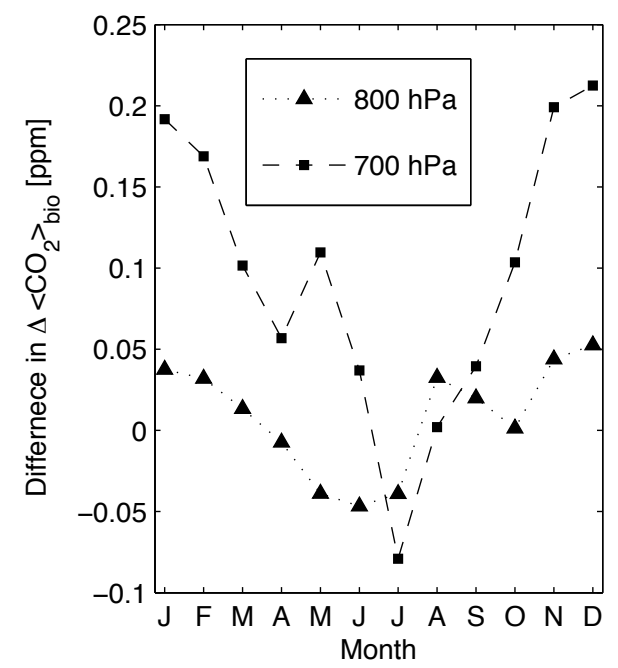

Fig. 17. Difference in the $30-60^{\circ} \mathrm{N}\left\langle\mathrm{CO}_{2}\right\rangle_{\text {bio }}$ contrast, averaged over North America $\left(180-300^{\circ} \mathrm{W}\right)$ when fluxes are emitted at two levels in AM2 versus at the surface.

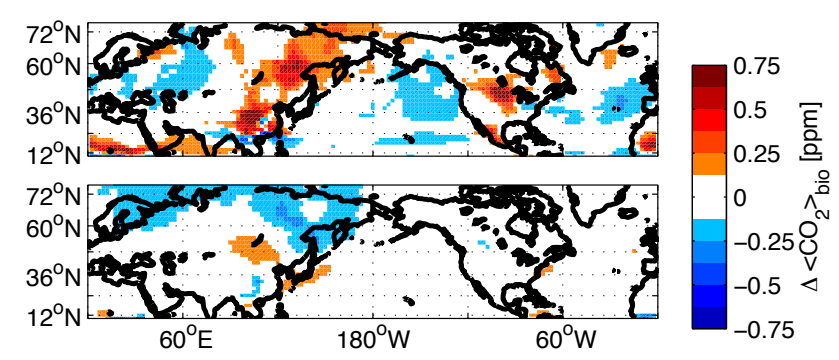

Fig. 18. (a) Difference in August-mean $\left\langle\mathrm{CO}_{2}\right\rangle_{\text {bio }}$ between simulations in which CASA fluxes are located above the boundary layer at $700 \mathrm{hPa}$ versus at the surface. (b) Same, except for February-mean $\left\langle\mathrm{CO}_{2}\right\rangle_{\text {bio. }}$.

Figure 18 shows a difference map between the $\left\langle\mathrm{CO}_{2}\right\rangle_{\text {bio }}$ from simulations with exchange at $700 \mathrm{hPa}$ and exchange at the surface during August (top) and February (bottom). Except over the Tibetan Plateau in summer, mean $\left\langle\mathrm{CO}_{2}\right\rangle_{\text {bio }}$ changes by less than $0.75 \mathrm{ppm}$ everywhere.

Although, in general, fluxes covary with meteorological variables such as temperature and boundary layer height, small-scale physics has little influence on the ultimate diagnostics, such as seasonal cycle amplitude or the estimated $\left.\partial_{y} \widehat{\left\langle\mathrm{CO}_{2}\right\rangle}\right\rangle$. This is illustrated in a comparison of $\left\langle\mathrm{CO}_{2}\right\rangle$ diagnostics at TCCON sites between AM2 and CarbonTracker, both run with the same fluxes. CarbonTracker uses reanalysis meteorology, so there are correlations between the fluxes and the dynamics, whereas in AM2, the fluxes and meteorology are independent. Both models yield similar seasonal cycle amplitudes (Table 1) and estimates for seasonal $\partial_{y} \widehat{\left\langle\mathrm{CO}_{2}\right\rangle}$ (Fig. 19) despite very different meteorology. Such results suggest that analysis of $\left\langle\mathrm{CO}_{2}\right\rangle$ using a dynamical coordinate such as $\theta$ may help mediate differences between models. 


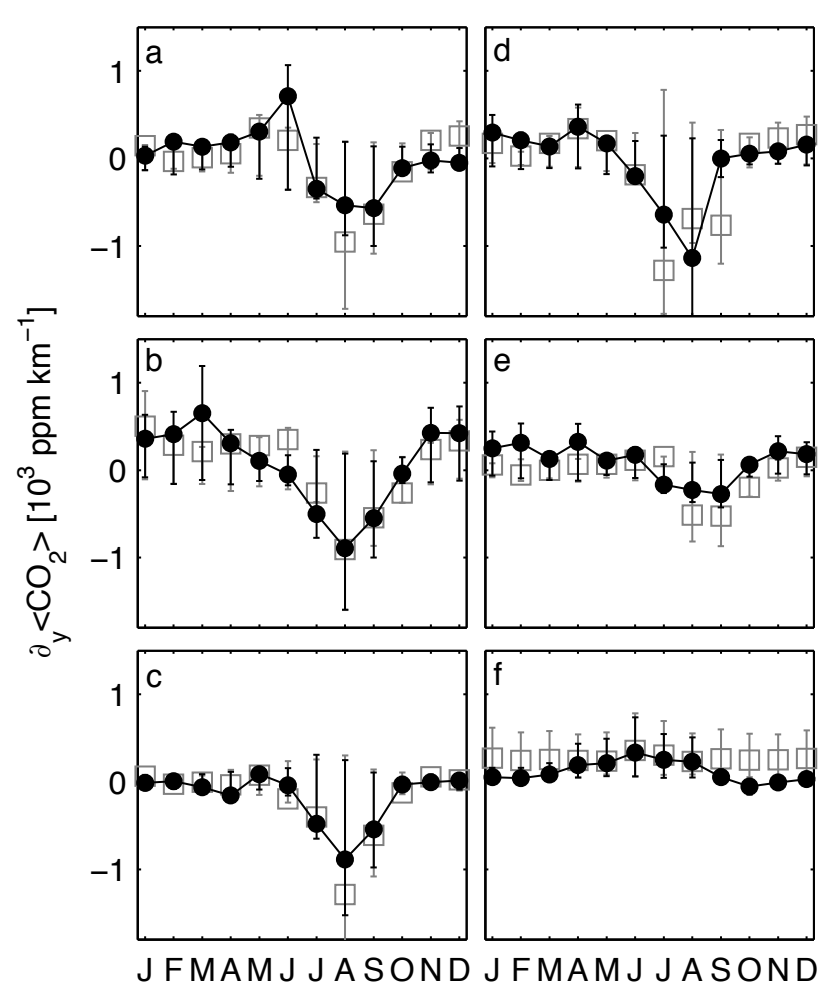

Fig. 19. Estimated $\partial \widehat{\partial\left\langle\mathrm{CO}_{2}\right\rangle}$ at six TCCON sites in AM2 (black circles) and in TM5 (gray squares) using identical surface fluxes. (a) Bialystok, Poland (b) Orleans, France (c) Park Falls, USA (d) Lamont, USA (e) Pasadena, USA (f) Lauder, New Zealand. The estimated gradients generally agree when the two models are driven with identical surface fluxes despite different meteorology.

Despite these encouraging results, studies have shown that the inversion of simulated $\left\langle\mathrm{CO}_{2}\right\rangle$ is sensitive to modelspecific transport (Chevallier et al., 2010). The extent to which transport errors are aliased into errors in the optimized fluxes is, however, quite sensitive to the spatial covariance structures specified in the inversion setup. The discussion in this paper of the footprint of $\left\langle\mathrm{CO}_{2}\right\rangle$ may help to inform the design of spatial covariance structures used in future inversions of $\left\langle\mathrm{CO}_{2}\right\rangle$.

\section{Conclusions}

Column-averaged $\left\langle\mathrm{CO}_{2}\right\rangle$ has a very large footprint. As such, variations in $\left\langle\mathrm{CO}_{2}\right\rangle$ are primarily determined by large-scale phenomena. Advection of large-scale $\left\langle\mathrm{CO}_{2}\right\rangle$ gradients on synoptic timescales dwarfs diurnal variations in all seasons. These gradients are set primarily by the north-south flux distribution. One implication of this finding is that analyses of $\left\langle\mathrm{CO}_{2}\right\rangle$ for flux constraints must use a global domain. Differences in $\left\langle\mathrm{CO}_{2}\right\rangle$ due to regional fluxes will be revealed only after the large-scale forcing is accounted for.
At midlatitude TCCON sites, much of the variability in $\left\langle\mathrm{CO}_{2}\right\rangle$ is tied to synoptic variability acting on large-scale gradients rather than to underlying fluxes. This fact complicates interpretation of sparse measurements without considering the larger domain. Accurate description of the mean state, however, does allow regional flux information to emerge. For example, in simulations with CASA fluxes, $\left\langle\mathrm{CO}_{2}\right\rangle$ from Bialystok is low in May relative to other sites when plotted as a function of meridional displacement (Fig. 15a) due to earlier regional onset of the growing season. In contrast, the Bialystok $\left\langle\mathrm{CO}_{2}\right\rangle$ from a simulation driven by zonal biospheric fluxes fall along a smooth curve with the other sites (Fig. 12c). Likewise, regional drawdown is evident in Park Falls in the experiment with CASA fluxes (Fig. 15a), where Park Falls $\left\langle\mathrm{CO}_{2}\right\rangle$ is $\sim 1.5 \mathrm{ppm}$ lower than in the zonally uniform flux experiment (Fig. 12c) during August, in agreement with the $\left\langle\mathrm{CO}_{2}\right\rangle$ difference at Park Falls in Fig. 7. Comparisons such as these provide quantitative information on the regional flux phasing and strength, even in the context of large-scale gradients.

The relative contribution of regional fluxes to $\left\langle\mathrm{CO}_{2}\right\rangle$ depends on gradients in the mean state. For instance, in the Northern Hemisphere the mean state is set by the biosphere. As the $\left\langle\mathrm{CO}_{2}\right\rangle_{\text {bio }}$ gradient increases in the amplified simulations, the relative contribution of regional fluxes diminishes. In Fig. 15a, regional fluxes draw down the Park Falls mean $\left\langle\mathrm{CO}_{2}\right\rangle_{\text {bio }}$ by $\sim 1.5 \mathrm{ppm}$ during summer, a large deviation relative to a total north-south gradient of only $3 \mathrm{ppm}$ across all TCCON sites. In Fig. 14b, the relative deviation is smaller because the large-scale signal is larger. To further illustrate, the relative effect of $\left\langle\mathrm{CO}_{2}\right\rangle_{\text {fossil }}$ decreases in experiments with CASA fluxes amplified in the boreal forests relative to standard CASA fluxes. The zonal contrasts in $\left\langle\mathrm{CO}_{2}\right\rangle_{\text {fossil }}$ shown in Fig. $3 \mathrm{~b}$ are masked by contrasts set by biospheric fluxes and dynamics. During the growing season, the contrast between eastern and western United States owing to eastern fossil fuel emissions is $\sim 0.3 \mathrm{ppm}$ while the contrast in $\left\langle\mathrm{CO}_{2}\right\rangle_{\text {bio }}$ over the same area is $\sim 1 \mathrm{ppm}$. In the simulation with enhanced boreal biospheric fluxes, this contrast increases to $\sim 1.5 \mathrm{ppm}$.

Recent studies suggest that vertical mixing in many transport models is sluggish in the mean (Yang et al., 2007; Nakatsuka and Maksyutov, 2009). Such errors have a large effect on near-surface $\left[\mathrm{CO}_{2}\right]$ simulations. As we show here, however, vertical mixing has only a small effect on simulated $\left\langle\mathrm{CO}_{2}\right\rangle$. In AM2, a gross error in mixing (e.g., by putting the fluxes in the troposphere) alters the north-south gradient across the Northern Hemisphere midlatitudes by at most $0.2 \mathrm{ppm}$. Although such a bias in the $\left\langle\mathrm{CO}_{2}\right\rangle$ gradient must be taken into account when working with satellite or groundbased $\left\langle\mathrm{CO}_{2}\right\rangle$, it suggests that the insensitivity of $\left\langle\mathrm{CO}_{2}\right\rangle$ to local surface fluxes extends to insensitivity to local vertical mixing. 
Because variations in $\left\langle\mathrm{CO}_{2}\right\rangle$ arise due to the large-scale gradients, the correlation of $\left\langle\mathrm{CO}_{2}\right\rangle^{\prime}$ with $\theta^{\prime}$ provides an important constraint. We anticipate that diagnostics such as the gradient $\partial_{y} \widehat{\left\langle\mathrm{CO}_{2}\right\rangle}$ estimated from covariations in $\left\langle\mathrm{CO}_{2}\right\rangle$ and $\theta$ can be used widely in total column and free tropospheric $\mathrm{CO}_{2}$ studies to better understand large-scale patterns in carbon fluxes. As demonstrated through AM2 simulations, $\partial_{y} \widehat{\left\langle\mathrm{CO}_{2}\right\rangle}$ is sensitive to the north-south flux distribution. In a companion manuscript, we illustrate the use of the relationship between $\left\langle\mathrm{CO}_{2}\right\rangle$ and $\theta$ variations to evaluate fluxes based on TCCON $\left\langle\mathrm{CO}_{2}\right\rangle$ data, free tropospheric data, and recent satellite observations. We illustrate that the estimated $\left\langle\mathrm{CO}_{2}\right\rangle$ gradient provides new constraints on the gross fluxes on continental scales.

Potential temperature, $\theta$, provides an alternative coordinate to compare multiple data sources. Commonly, $\mathrm{CO}_{2} \mathrm{ob}-$ servations from different platforms are compared by averaging in time and space to satisfy coincidence criteria. Such averaging aliases error because of the large temporal and spatial variations in free tropospheric $\mathrm{CO}_{2}$, associated with synoptic atmospheric variability. Instead, free tropospheric $\theta$ or $L$ can be used as a conditional averaging coordinate. Satellite $\left\langle\mathrm{CO}_{2}\right\rangle$ will provide spatially and temporally dense data sets of modest precision, which can be statistically compared to $\left\langle\mathrm{CO}_{2}\right\rangle$ from other, more precise data sources using this approach.

Variations in $\mathrm{CO}_{2}$ concentration are the driver of atmospheric inversion studies to infer $\mathrm{CO}_{2}$ fluxes, so it is crucial to attribute these variations correctly, either to the mean state or to other factors, such as flux variability. Because largescale gradients generate temporal variability through synoptic activity acting on them, accurate estimation of the northsouth gradients ensures that the major source of variations in $\left\langle\mathrm{CO}_{2}\right\rangle$ is captured. These simulations suggest that $\left\langle\mathrm{CO}_{2}\right\rangle$ has a unique niche to fill in carbon cycle science, as it provides a strong constraint on large-scale flux estimates. In contrast, extracting information about regional scales (e.g. fossil fuel emissions) will be challenging. Coupled with data obtained at the surface and in the free troposphere, however, both large-scale and regional flux estimates should improve.

Acknowledgements. We thank Peter Rayer and Dietrich Feist for helpful reviews of this manuscript. Support for this work from the NASA Carbon Cycle Program grant NNX08AI86G is gratefully acknowledged. GKA acknowledges support from a NSF graduate fellowship and an AAUW dissertation fellowship. The simulations shown were performed on Caltech's Division of Geological and Planetary Sciences Dell cluster. CarbonTracker 2009 data were provided by NOAA ESRL, Boulder, Colorado, USA from the website at http://carbontracker.noaa.gov.

Edited by: C. Gerbig

\section{References}

Anderson, J. L., Balaji, V., Broccoli, A. J., Cooke, W. F., Delworth, T. L., Dixon, K. W., Donner, L. J., Dunne, K. A., Freidenreich, S. M., Garner, S. T., Gudgel, R. G., Gordon, C. T., Held, I. M., Hemler, R. S., Horowitz, L. W., Klein, S. A., Knutson, T. R., Kushner, P. J., Langenhost, A. R., Lau, N. C., Liang, Z., Malyshev, S. L., Milly, P. C. D., Nath, M. J., Ploshay, J. J., Ramaswamy, V., Schwarzkopf, M. D., Shevliakova, E., Sirutis, J. J., Soden, B. J., Stern, W. F., Thompson, L. A., Wilson, R. J., Wittenberg, A. T., and Wyman, B. L.: The new GFDL global atmosphere and land model AM2-LM2: Evaluation with prescribed SST simulations, J. Climate, 17, 4641-4673, 2004.

Andres, R. J., Marland, G., Fung, I., and Matthews, E.: A $1 \times 1$ Distribution of Carbon Dioxide Emissions From Fossil Fuel Consumption and Cement Manufacture, Global Biogeochem. Cy., 10, 419-429, doi:10.1029/96GB01523, 1996.

Chevallier, F., Breon, F. M., and Rayner, P. J.: Contribution of the Orbiting Carbon Observatory to the estimation of $\mathrm{CO}_{2}$ sources and sinks: Theoretical study in a variational data assimilation framework, J. Geophys. Res.-Atmos., 112, D09307, doi:10.1029/2006JD007375, 2007.

Chevallier, F., L. Feng, H. Bosch, P. I. Palmer, and Rayner,P. J.: On the impact of transport model errors for the estimation of surface fluxes from GOSAT observations, Geophys. Res. Lett., 37, L21803, doi:10.1029/2010GL044652, 2010.

Ciais, P., Tans, P. P., Trolier, M., White, J. W. C., and Francey, R. J.: A Large Northern-hemisphere Terrestrial $\mathrm{CO}_{2}$ Sink Indicated By the C-13/C-12 Ratio of Atmospheric $\mathrm{CO}_{2}$, Science, 269, 1098$1102,1995$.

Crisp, D., Atlas, R. M., Breon, F. M., Brown, L. R., Burrows, J. P., Ciais, P., Connor, B. J., Doney, S. C., Fung, I. Y., Jacob, D. J., Miller, C. E., O’Brien, D., Pawson, S., Randerson, J. T., Rayner, P., Salawitch, R. J., Sander, S. P., Sen, B., Stephens, G. L., Tans, P. P., Toon, G. C., Wennberg, P. O., Wofsy, S. C., Yung, Y. L., Kuang, Z. M., Chudasama, B., Sprague, G., Weiss, B., Pollock, R., Kenyon, D., and Schroll, S.: The orbiting carbon observatory (OCO) mission, "Trace constituents in the troposphere and lower stratosphere" in the book series, Adv. Space Res., 34, 700-709, 2004.

Denning, A. S., Fung, I. Y., and Randall, D.: Latitudinal Gradient of Atmospheric $\mathrm{CO}_{2}$ Due To Seasonal Exchange With Land Biota, Nature, 376, 240-243, 1995.

Gurney, K. R., Law, R. M., Denning, A. S., Rayner, P. J., Baker, D., Bousquet, P., Bruhwiler, L., Chen, Y.-H., Ciais, P., Fan, S., Fung, I. Y., Gloor, M., Heimann, M., Higuchi, K., John, J., Maki, T., Maksyutov, S., Masarie, K., Peylin, P., Prather, M., Pak, B. C., Randerson, J., Sarmiento, J., Taguchi, S., Takahashi, T., and Yuen, C.-W.: Towards robust regional estimates of $\mathrm{CO}_{2}$ sources and sinks using atmospheric transport models, Nature, 415, 626-630, doi:10.1038/415626a, 2002.

Gurney, K. R., Law, R. M., Denning, A. S., Rayner, P. J., Pak, B. C., Baker, D., Bousquet, P., Bruhwiler, L., Chen, Y. H., Ciais, P., Fung, I. Y., Heimann, M., John, J., Maki, T., Maksyutov, S., Peylin, P., Prather, M., and Taguchi, S.: Transcom 3 inversion intercomparison: Model mean results for the estimation of seasonal carbon sources and sinks, Global Biogeochem. Cy., 18, GB1010, doi:10.1029/2003GB002111,2004.

Hovmöller, E., The trough and ridge diagram: Tellus, 1, 62-66, 1949. 
Le Quéré, C., Raupach, M. R., Canadell, J. G., Marland, G., Bopp, L., Ciais, P., Conway, T. J., Doney, S. C., Feely, R. A., Foster, P., Friedlingstein, P., Gurney, K., Houghton, R. A., House, J. I., Huntingford, C., Levy, P. E., Lomas, M. R., Majkut, J., Metzl, N., Ometto, J. P., Peters, G. P., Prentice, I. C., Randerson, J. T., Running, S. W., Sarmiento, J. L., Schuster, U., Sitch, S., Takahashi, T., Viovy, N., van der Werf, G. R., and Woodward, F. I.: Trends in the sources and sinks of carbon dioxide, Nature Geosci., 2, 831-836, 2009.

Lin, S. J.: A "vertically Lagrangian" finite-volume dynamical core for global models, Mon. Weather Rev., 132, 2293-2307, 2004.

Marland, G. and Rotty, R. M.: Carbon-dioxide Emissions From Fossil-fuels - A Procedure For Estimation and Results For 19501982, Tellus B, 36, 232-261, 1984.

Miyazaki, K., Patra, P. K., Takigawa, M., Iwasaki, T., and Nakazawa, T.: Global-scale transport of carbon dioxide in the troposphere, J. Geophys. Res., 113, D15301, doi:10.1029/2007JD009557, 2008.

Miyazaki, K., Machida, T., Patra, P. K., Iwasaki, T., Sawa, Y., Matsueda, H., and Nakazawa, T.: Formation mechanisms of latitudinal $\mathrm{CO}_{2}$ gradients in the upper troposphere over the subtropics and tropics, J. Geophys. Res., 114, D03306, doi:10.1029/2008JD010545, 2009.

Nakatsuka, Y. and Maksyutov, S.: Optimization of the seasonal cycles of simulated $\mathrm{CO}_{2}$ flux by fitting simulated atmospheric $\mathrm{CO}_{2}$ to observed vertical profiles, Biogeosciences, 6, 27332741, doi:10.5194/bg-6-2733-2009, 2009.

Nevison, C. D., Mahowald, N. M., Doney, S. C., Lima, I. D., Van der Werf, G. R., Randerson, J. T., Baker, D. F., Kasibhatla, P., and McKinley, G. A.: Contribution of ocean, fossil fuel, land biosphere, and biomass burning carbon fluxes to seasonal and interannual variability in atmospheric $\mathrm{CO}_{2}$, J. Geophys. Res.Biogeo., 113, G01010, doi:10.1029/2007JG000408, 2008.

Olsen, S. C. and Randerson, J. T.: Differences between surface and column atmospheric $\mathrm{CO}_{2}$ and implications for carbon cycle research, J. Geophys. Res., 109, D02301, doi:10.1029/2003JD003968, 2004.

Parrington, M., Jones, D. B. A., Bowman, K. W., Thompson, A. M., Tarasick, D. W., Merrill, J., Oltmans, S. J., Leblanc, T., Witte, J. C, and Millet, D. B.: Impact of the assimilation of ozone from the Tropospheric Emission Spectrometer on surface ozone across North America, Geophys. Res. Lett., 36, L04802, doi:10.1029/2008GL036935, 2009.

Peters, W., Jacobson, A. R., Sweeney, C., Andrews, A. E., Conway, T. J., Masarie, K., Miller, J. B., Bruhwiler, L. M. P., Pétron, G., Hirsch, A. I., Worthy, D. E. J., van der Werf, G. R., Randerson, J. T., Wennberg, P. O., Krol, M. C., and Tans, P. P.: An atmospheric perspective on North American carbon dioxide exchange: CarbonTracker, P. Natl. Acad. Sci., 104, 18925-18930, doi:10.1073/pnas.0708986104, 2007.
Piao, S. L., Ciais, P., Friedlingstein, P., Peylin, P., Reichstein, M., Luyssaert, S., Margolis, H., Fang, J. Y., Barr, A., Chen, A. P., Grelle, A., Hollinger, D. Y., Laurila, T., Lindroth, A., Richardson, A. D., and Vesala, T.: Net carbon dioxide losses of northern ecosystems in response to autumn warming, Nature, 451, 49-53, 2008.

Randerson, J. T., Thompson, M. V., Conway, T. J., Fung, I. Y., and Field, C. B.: The contribution of terrestrial sources and sinks to trends in the seasonal cycle of atmospheric carbon dioxide, Global Biogeochem. Cy., 11, 535-560, 1997.

Sawa, Y., Machida, T., and Matsueda, H.: Seasonal variations of $\mathrm{CO}_{2}$ near the tropopause observed by commercial aircraft, J. Geophys. Res.-Atmos., 113, D23301, doi:10.1029/2008JD010568, 2008.

Stephens, B. B., Gurney, K. R., Tans, P. P., Sweeney, C., Peters, W., Bruhwiler, L., Ciais, P., Ramonet, M., Bousquet, P., Nakazawa, T., Aoki, S., Machida, T., Inoue, G., Vinnichenko, N., Lloyd, J., Jordan, A., Heimann, M., Shibistova, O., Langenfelds, R. L., Steele, L. P., Francey, R. J., and Denning, A. S.: Weak northern and strong tropical land carbon uptake from vertical profiles of atmospheric $\mathrm{CO}_{2}$, Science, 316, 1732-1735, 2007.

Takahashi, T., Sutherland, S. C., Sweeney, C., Poisson, A., Metzl, N., Tilbrook, B., Bates, N., Wanninkhof, R., Feely, R. A., Sabine, C., Olafsson, J., and Nojiri, Y.: Global sea-air $\mathrm{CO}_{2}$ flux based on climatological surface ocean $p \mathrm{CO}_{2}$, and seasonal biological and temperature effects, Deep-Sea Res. Pt II, 49, 1601-1622, 2002.

Washenfelder, R. A., Toon, G. C., Blavier, J.-F., Yang, Z., Allen, N. T., Wennberg, P. O., Vay, S. A., Matross, D. M., and Daube, B. C.: Carbon dioxide column abundances at the Wisconsin Tall Tower site, J. Geophys. Res., 111, D22305, doi:10.1029/2006JD007154, 2006.

Yang, Z., Washenfelder, R. A., Keppel-Aleks, G., Krakauer, N. Y., Randerson, J. T., Tans, P. P., Sweeney, C., and Wennberg, P. O.: New constraints on Northern Hemisphere growing season net flux, Geophys. Res. Lett., 34, L12807, doi:10.1029/2007GL029742, 2007.

Yokota, T., Yoshida, Y., Eguchi, N., Ota, Y., Tanaka, T., Watanabe, H., and Maksyutov, S.: Global Concentrations of $\mathrm{CO}_{2}$ and $\mathrm{CH}_{4}$ Retrieved from GOSAT: First Preliminary Results, Sola, 5, 160163, 2009. 